\title{
Research on Innovation Evaluation of Tourism E-commerce in the
}

\author{
Process View \\ Xiya Wang ${ }^{1}$ \\ Xi'an Peihua University ${ }^{1}$, Shaanxi, Xi'an, 710125
}

Keywords: Tourism E-commerce; Diffusion of Innovation; Analytic Hierarchy Process; Fuzzy Synthetic Evaluation

\begin{abstract}
By the theory of innovation diffusion, this paper proposes an assessment and measurement system of tourism E-commerce innovation diffusion in the process view. With the data collection of survey, tourism E-commerce innovation diffusion is analyzed comparatively by selecting Ctrip.com and Tuniu and other tourist enterprises. The findings shows that the proper order of affective importance on tourism E-commerce innovation diffusion is followed by Sale and After-sale, Product R\&D, Production/Operation, Purchase/Supply. So enterprises should make corresponding investment according to the importance of each factor so as to promote the rapid development of tourism E-commerce.
\end{abstract}

\section{Introductions}

In recent years, few researches are on tourism E-commerce though every government, the academic circle and enterprises have started the study on diffusion measurement of E-commerce. At present in China, the research on the diffusion measurement index of E-commerce is simplex, which can not state out the integrating status between tourism E-commerce and tourism business process, which can not point out the existing problems and which can not solve the concerning problems between the government and enterprises. In order to push the innovation development of tourism E-commerce and to improve the enterprise core competition, this thesis attempts to narrow such a gap in the research to be aimed at building up an assessment and measurement model of tourism e-commerce innovation diffusion in the process view, which can measure and evaluate objectively the diffusion status of tourism E-commerce and can reveal the degree and feature of E-commerce integration into tourism business process.

\section{Theoretical Basis}

E-commerce is defined as the buying and selling on the internet. But the E-commerce in this thesis refers to the generalized definition proposed by Magal in 2001. That is to say E-commerce is a kind of internet or relevant technology activity to help enterprises operate effectively ${ }^{[1]}$.

\subsection{Innovation Diffusion Theory}

The successful E-commerce is one of the important information technology innovations for contemporary enterprises since E-commerce is a new field ${ }^{[2]}$. The research on information technology innovation diffusion indicates that only after the innovation is integrated into enterprise value chain, it can bring out outstanding business value, on the condition that the enterprise corresponding business process should be changed and should be integrated with innovation ${ }^{[3]}$.According to the three classifications of innovation proposed by famous Swanson in 2004, E-commerce belongs to III type of innovation. The main point is that E-commerce can accomplish its maximize prospective earning in the wide and deep supporting to business process and activities only after enterprise E-commerce is integrated into its core business process, or basic products/services and integrates them into suppliers and customers on the value chain. Starting from the innovation diffusion measurement of tourism E-commerce, this thesis is helpful to analyze the implementation effect and development of tourism E-commerce.

\subsection{View of Process}

The view of process originated from the approach to the past shows that the information technology value should embody the effect of technology to operational action and business process. So based on the feature in the view of 
process, the effect of technology on business process would be the research point and analysis unit.

In the view of process, the writer takes the effect of technology on business process as the analysis unit to research on E-commerce diffusion. By integrating enterprise E-commerce into business operation according to the electronic execution degree of operational process on the value chain, the writer proposes the measurement index system and the computing method in breadth and depth of E-commerce diffusion so as to examine and explain the differences and features of enterprise E-commerce business

\subsection{Research on Enterprise E-commerce Innovation Diffusion}

Research on enterprise E-commerce innovation diffusion mostly focuses on the adoption and un-adoption of E-commerce. The diffusion effect of economic indicators is proposed, for example online income /online sales/online purchase amount percentage ${ }^{[4]}$, or specific application of E-commerce. But all these can not indicate the enterprise whole business activity support of E-commerce. Another kind of research points to E-commerce diffusion degree and the regular degree of diffusion in the process, which indicates E-commerce as the application of internet relevant technology. Some researches divide E-commerce diffusion into serious phases to analyze diffusion process, whereas other researches take E-commerce as a whole. For example, the project of Information and Communication Technology in US Department of Commerce is on the operational process and capability of E-commerce. Fewer researches focus on the measurement system of enterprise E-commerce diffusion in the view of process. So all the relevant researches can not explain the tourism E-commerce support on business process.

\subsection{Research on Tourism E-commerce Innovation Diffusion}

There are few relevant researches on tourism E-commerce innovation diffusion in China. If you retrieve references through CNKI by typing key words as tourism E-commerce innovation diffusion or tourism E-commerce innovation, you will find nothing information. It is un-known about the whole implementation effect of tourism E-commerce. There is no measurement standard on tourism diffusion degree. So it is worthy in this thesis studying on tourism E-commerce innovation diffusion.

\section{Assessment System of Tourism E-commerce Innovation Diffusion}

\subsection{Assessment Index System}

Combining with tourism E-commerce characteristic and the core business process on the value chain, this thesis proposes the assessment index system of tourism E-commerce in percentage, as illustrated in the table 1.

\subsection{Breadth index}

Diffusion breadth index $(\boldsymbol{B})$ refers to the electronic executed business activities in percentage. Hereby the breadth of tourism E-commerce can be measured.

\subsection{Depth Index}

Diffusion depth index $(\boldsymbol{D})$ indicates the importance of electronic executed business activities, as illustrated in Table 1 . This article is going to calculate the index by MFSE, Multi-lay vague synthetic evaluation method.

\section{Empirical Analysis}

\subsection{Sample Selection}

10 selected tourism companies ( 5 online tourist suppliers and 5 traditional travel agency) can be the study samples to be investigated.

\subsection{Analysis on Diffusion Breadth}

The diffusion breadth index score from the sample tourist enterprises is indicated in the following table 1 .

\begin{tabular}{c|c|c|c|c|c|c|c|c|c|c}
\multicolumn{7}{c}{ Table 1 } & \multicolumn{1}{c}{ The Diffusion Breadth Index Score from the Sample Tourism Enterprises } & unit: \\
\hline \multirow{2}{*}{$\begin{array}{c}\text { Diffusion } \\
\text { Breadth Index }\end{array}$} & Ctrip. & Qunar & Tuniu & Qyer & CNCNcom & China & China & UTS Travel & Haiwai & Spring and Autumn \\
\cline { 2 - 11 } & 90 & 80 & 95 & 60 & 50 & 70 & 55 & 65 & 50 & 50 \\
\hline
\end{tabular}

Table 1 shows that E-commerce of online travel service suppliers such as Tuniu, ctrip.com, Qunar, etc. is applied more widely, whereas the score of the traditional travel agency such as China CYTS, China Comfort Travel is 
lower, which implies that they are in the process of transition towards internet platform.

\subsection{Analysis on Diffusion Depth}

\section{(1) Choose Object Set for Evaluation}

$X=\left\{x_{1}, x_{2}, \ldots, x_{10}\right\}$

$=\{$ Ctrip. Com, Qunar, Tuniu, Qyer, CNCNcom, China CYTS, China Comfort Travel, UTS Travel, Haiwai, Spring and Autumn Travel \}

\section{(2) Confirm Assessment Index Set and Evaluation Set}

Assessment index set is as the followings patterns:

$U=\left\{u_{1}, u_{2}, u_{3}, u_{4}\right\}=\{$ product $\mathrm{R} / \mathrm{D}$, purchase/supply, production/management, sale/after-sale $\}$ 。

Assessment set is supposed as $P$.

$P^{T}=($ very good, better, general, bad, very bad $)=\left(\begin{array}{lllll}100 & 80 & 60 & 40 & 20\end{array}\right) 。$

\section{(3) Calculate the Weight Set of Indicators}

According to the score by expert, weight set of first grade index by AHP is as the followings:

$$
W=\left(\begin{array}{llllll}
w_{1} & w_{2} & w_{3} & w_{4}
\end{array}\right)^{\mathrm{T}}=\left(\begin{array}{llll}
0.2893 & 0.1062 & 0.1715 & 0.4330
\end{array}\right)
$$

Weight set of second grade index shows $W\left(u_{1}\right) 、 W\left(\mathrm{u}_{2}\right) 、 W\left(\mathrm{u}_{3}\right) 、 W\left(\mathrm{u}_{4}\right)$ as the following:

$$
\begin{aligned}
& W\left(u_{1}\right)=\left(\begin{array}{lll}
w_{11} w_{12} & w_{13}
\end{array}\right)^{\mathrm{T}}=\left(\begin{array}{lll}
0.5936 & 0.1571 & 0.2493
\end{array}\right) \\
& W\left(\mathbf{u}_{2}\right)=\left(\begin{array}{llllll}
w_{21} & w_{22} & \ldots w_{25}
\end{array}\right)^{\mathrm{T}}=\left(\begin{array}{lllll}
0.1693 & 0.3014 & 0.0784 & 0.3414 & 0.1094
\end{array}\right) \\
& W\left(\mathrm{u}_{3}\right)=\left(\begin{array}{lllll}
w_{31} & w_{32} \ldots w_{44}
\end{array}\right)^{\mathrm{T}}=\left(\begin{array}{llll}
0.4937 & 0.0784 & 0.1769 & 0.2510
\end{array}\right)
\end{aligned}
$$

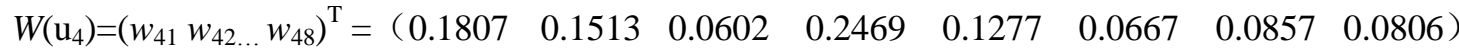

\section{(4) Confirm Judgement Matrix}

Judgement Matrix $A: X \times U \rightarrow[0,1], a_{i j}=C\left(x_{i}, u_{j}\right) \in[0,1]$, refers to the characteristic index of Object $x_{i}$ on Object $u_{j}$, indicates the score of every enterprise on all different grade index.In order to get accurate data, the writer hands out 500 questionnaires to the people with experience in tourism products shopping and gets back 468 ones. So, the score of $a_{i j}$ in this paper is analyzed by the data coming from the survey, in which there are 5 different levels of scale interval, such as very good, better, general, bad, very bad, which are indicated by $1 、 2 、 3$ 、 4、5. The score of qualitative index(Example as $u_{11}, u_{12}, u_{13}, u_{22}, u_{48}$ )is calculated by the scale interval percentage in the survey (take the score of ctrip. com as the example in table 3-3); The score of quantitative index comes from the above 5 different levels of scale interval. Judgment Matrix of qualitative index for sample enterprises is supposed $A^{\prime}$. Then, the data is as the followings:

$$
A^{\prime}=\left(\begin{array}{llllllllll}
5 & 4 & 5 & 4 & 2 & 2 & 2 & 3 & 3 & 2 \\
1 & 1 & 4 & 1 & 1 & 1 & 1 & 1 & 1 & 1 \\
4 & 3 & 3 & 1 & 2 & 2 & 2 & 2 & 1 & 1 \\
4 & 3 & 1 & 1 & 1 & 2 & 1 & 1 & 1 & 1 \\
5 & 4 & 5 & 4 & 3 & 3 & 3 & 2 & 2 & 1 \\
4 & 1 & 2 & 3 & 1 & 4 & 4 & 4 & 1 & 3 \\
4 & 5 & 4 & 3 & 3 & 1 & 1 & 3 & 1 & 1 \\
5 & 4 & 3 & 1 & 1 & 2 & 1 & 1 & 3 & 3 \\
4 & 0 & 4 & 1 & 1 & 3 & 4 & 1 & 1 & 1 \\
4 & 4 & 5 & 3 & 2 & 4 & 3 & 3 & 2 & 2 \\
1 & 1 & 1 & 1 & 1 & 1 & 1 & 1 & 1 & 3 \\
3 & 1 & 3 & 1 & 2 & 1 & 4 & 3 & 3 & 2 \\
4 & 3 & 4 & 3 & 3 & 4 & 1 & 2 & 1 & 2 \\
4 & 3 & 4 & 3 & 3 & 4 & 1 & 2 & 1 & 2 \\
4 & 3 & 3 & 1 & 1 & 1 & 1 & 1 & 1 & 1
\end{array}\right)
$$


Above all, the index weight and score of Ecommerce diffusion depth in Ctrip. Com Travel Enterprise are as table 2 shows.

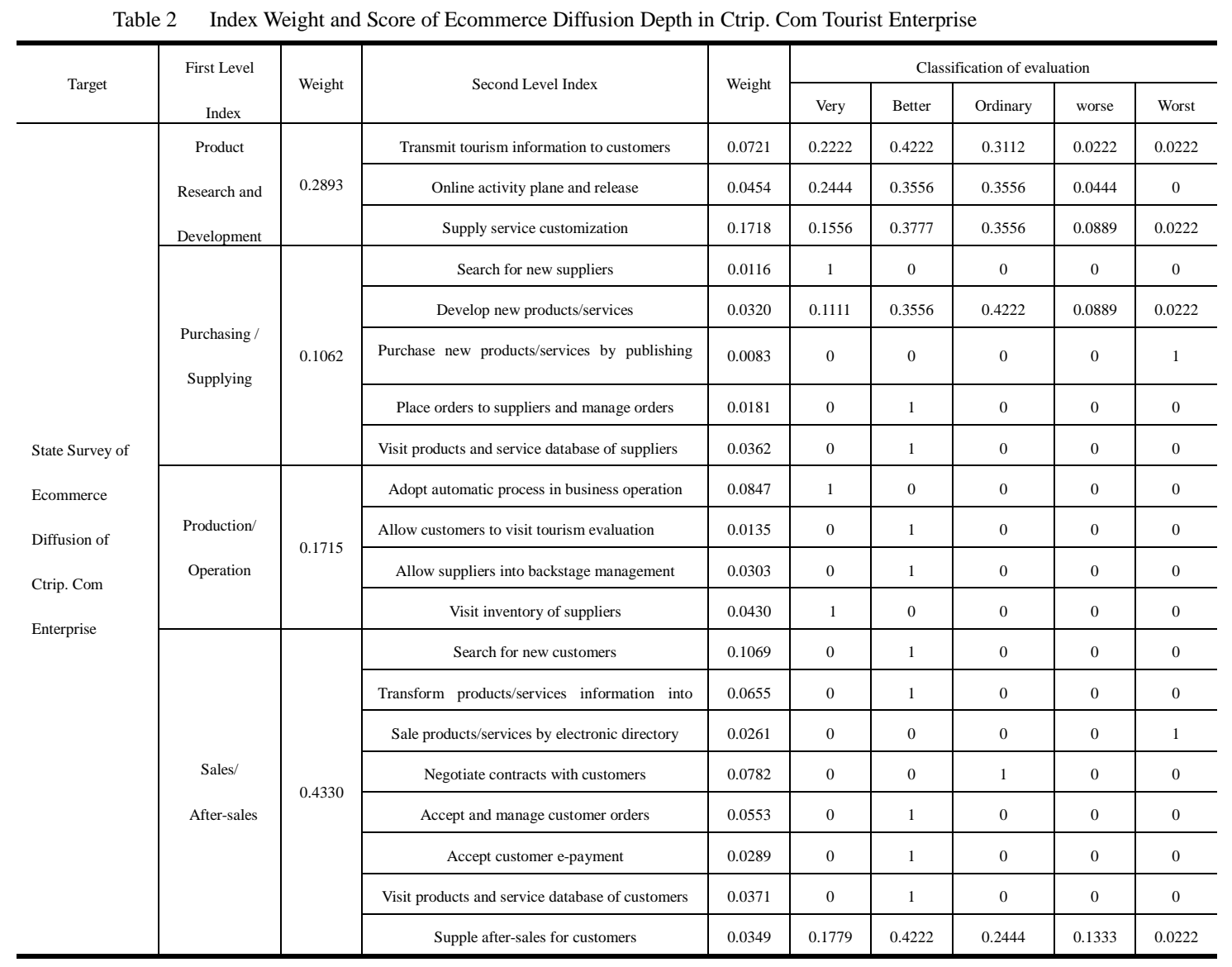

\section{(5) Fuzzy Evaluation}

Taking the state of Ecommerce diffusion of Ctrip.com as example (illustrated in table 4), this paper gets the fuzzy evaluation result in weight average type calculation as in the followings.

First level evaluation Matrix is as the following:

$R=W \circ A$

$$
\begin{aligned}
& =\left(\begin{array}{llll}
0.2893 & 0.1062 & 0.1715 & 0.433
\end{array}\right) \circ \quad\left(\begin{array}{lllll}
0.2091 & 0.4006 & 0.3292 & 0.0423 & 0.0187 \\
0.2028 & 0.5580 & 0.1273 & 0.0268 & 0.0851 \\
0.7447 & 0.2553 & 0 & 0 & 0 \\
0.0143 & 0.6461 & 0.2666 & 0.0107 & 0.0620
\end{array}\right) \\
& =\left(\begin{array}{lllll}
0.2159 & 0.4987 & 0.2242 & 0.0197 & 0.0413
\end{array}\right)
\end{aligned}
$$

Second level evaluation Matrix is as the following:

$R\left(u_{1}\right)=W\left(u_{1}\right) \circ A\left(u_{1}\right)$

$$
\begin{aligned}
& =\left(\begin{array}{lll}
0.5936 & 0.1571 & 0.2493
\end{array}\right) \circ\left(\begin{array}{lllll}
0.2222 & 0.4222 & 0.3112 & 0.0222 & 0.0222 \\
0.2444 & 0.3556 & 0.3556 & 0.0444 & 0 \\
0.1556 & 0.3777 & 0.3556 & 0.0889 & 0.0222
\end{array}\right) \\
& =\left(\begin{array}{lllll}
0.2091 & 0.4006 & 0.3292 & 0.0423 & 0.0187
\end{array}\right) \\
& R\left(u_{3}\right)=W\left(u_{3}\right) \circ A\left(u_{3}\right)=\left(\begin{array}{lllll}
0.7447 & 0.2553 & 0 & 0 & 0
\end{array}\right) \\
& R\left(u_{4}\right)=W\left(u_{4}\right) \circ A\left(u_{4}\right)=\left(\begin{array}{lllll}
0.0143 & 0.6461 & 0.2666 & 0.0107 & 0.0620
\end{array}\right)
\end{aligned}
$$

So, based on assessment set $P$, E-commerce diffusion depth index of Ctrip.com is as the followings:

$D=R \circ P=\left(\begin{array}{llllllll}0.2159 & 0.4987 & 0.2242 & 0.0197 & 0.0413\end{array}\right)^{\circ}\left(\begin{array}{lllll}100 & 80 & 60 & 40 & 20\end{array}\right)^{\mathrm{T}}=76.5601$ 
In the same way, the E-commerce diffusion depth indexes of other sample travel enterprises are illustrated in following table 3 .

\begin{tabular}{c|c|c|c|c|c|c|c|c|c|c}
\multicolumn{7}{c}{ Table3 Ecommerce Diffusion Depth Indexes of Sample Travel Enterprises } \\
\hline \multirow{2}{*}{$\begin{array}{c}\text { Depth Index } \\
\text { D }\end{array}$} & Ctrip.Com & Qunar & Tuniu & Qyer & CNCN.Com & China & China & UTS & Haiwai & Spring and Autumn Travel \\
\cline { 2 - 12 } & 76.560 & 62.938 & 74.712 & 51.236 & 50.231 & 56.155 & 56.620 & 57.798 & 49.135 & 46.372 \\
\hline Research \& & 74.781 & 70.973 & 72.765 & 67.029 & 64.378 & 71.970 & 69.254 & 71.499 & 71.329 & 69.602 \\
\hline Purchase/ & 75.325 & 62.522 & 66.369 & 41.140 & 43.474 & 46.331 & 44.545 & 48.869 & 41.505 & 39.191 \\
\hline Production/ & 94.894 & 78.834 & 81.718 & 59.834 & 46.824 & 49.472 & 44.452 & 41.654 & 39.914 & 33.176 \\
\hline Marketing/ & 70.790 & 51.375 & 75.284 & 39.756 & 43.786 & 50.645 & 55.961 & 57.227 & 39.829 & 37.838 \\
\hline
\end{tabular}

\subsection{Implication for Research and Practice}

\section{(1) Diffusion Breadth}

According to the Ecommerce innovation diffusion breadth of sample enterprises, tourist enterprise Ecommerce diffusion mainly focuses on products R\&D, Marketing and After-sale. The application of it on operator and purchase should be reinforced because of the weak data.

\section{(2) First level Fuzzy Evaluation}

Table 3 indicates that the top three Ecommerce diffusion indexes are coming from Ctrip.Com, Tuniu and Qunar, whose data are generally above average. Others are on lower level, among which Ecommerce diffusion indexes from Haiwai, Spring \& Autumn Travel are lowest. Generally speaking, all the sample tourist enterprises have great development space in Ecommerce innovation diffusion.

\section{(3) Second Level Fuzzy Evaluation}

Table 5 indicates the following consequence:

In terms of product $\mathrm{R} \& \mathrm{D}$, the E-commerce diffusion depth of 10 tourist enterprises is above average. As a well-known domestic tourist service supplier, E-commerce of Ctrip. Com Tourist Enterprise has been deeply applied, closely followed by Qunar and Tuniu. The large scale tourist enterprises such as China CYTS, UTS Travel, Haiwai have been transferring into online tour suppliers by actively developing E-commerce. E-commerce application of Qyer, CNCN.Com, China Comfort Travel, Spring and Autumn Travel is below the average. So according to their own status, these enterprises need to adjust development strategy without delay.

In terms of Purchase/Supply, three tourist enterprises, such as Ctrip.Com, Qunar, Tuniu, develop well above-average, but each of them has $10 \%$ index difference in between, which indicates such barriers to the E-commerce application that these tourist enterprises need to adjust strategy according to their status. E-commerce application of other tourist enterprises is below-average, mainly on traditional travel agencies, which explains that these enterprises have not stepped on the complicated E-commerce stage yet. So they need to start gradually developing enterprise E-commerce.

In terms of Production/Operation, index from Ctrip.com is higher than other enterprises in the peer, who has got into the business of negotiation with customers and suppliers; Next is Tuniu and Qunar, who are above average; Other enterprises are below-average, still in the preliminary engagement, similar as their E-commerce application in terms of Purchase/Supply.

In terms of Sale/After-sale, overall effect of ten tourist enterprises are not perfect, among which index of Tuniu is 75.284 who runs the first. Ctrip.com runs closely after. The rest of enterprises are in the lower level. The E-commerce diffusion of Spring and Autumn Travel is lowest all in all, who has not started its E-commerce yet in the process as contract negotiation with customers, accept and manage customer orders.

The above weights are known as sale and after sale > product research > production/operation > purchase/supply. In measurement index system of tourism E-commerce innovation diffusion, the weight of Sale/ 
After-sale is maximum. Compared with the weight average of 10 enterprises in B1, B2, B3, B4, we can see in terms of sale and after-sale that there is such a lack level of 10 enterprise E-commerce diffusion that they must call their attention and build up perfect customer management system and product database. They need to start their strict management in customer information and order form so as to increase business execution efficiency and customer satisfaction. In terms of Product R/D, 10 enterprises are not in good status. Although Ctrip.com is comparatively better. It is just above average. So tourist enterprises must enhance feature products research; in terms of Production/Operation, traditional tourist enterprises should better change marketing concept, learn from online enterprises, make a correct understanding of the advantage to apply advanced information technology, actively take means of E-commerce to run enterprise activities; In terms of Purchase/Supply, tourist enterprises need to comprehend the significance of E-bidding, improve procurement efficiency, promote the electronic business process, so that tourist enterprises can step up to the higher E-commerce stage.

\section{Conclusion}

The research finds that the breadth and depth in E-commerce diffusion of online tourist services are higher than that of traditional ones. Since the proper order of important degree to influence tourist E-commerce diffusion is as Sale/After-sale, Product R\&D, Production/Operation, Purchase/Supply, tourist enterprises should better reallocate resources according to the proper order of their own E-commerce importance.

Conclusively there are four important suggestions to tourist enterprises: (1) In Product R\&D, featured tourism projects should be focused on research and development so that customer demand can be satisfied in the growing trend of tourist market; (2) In Purchase/Supply, collaborative commerce between enterprises and partners like suppliers should be established to realize information sharing and information fast transmission in the low procedure cost; (3) In Production/Operation, automatic operation flow should be founded to improve business treatment efficiency; (4) In Sale/After-sale, customers should be paid a return visit in time to improve two-ways communication and optimize product and service program to enhance customer degree of adhesion. By all means, in the specific implementation process, the weight order of three grade indicators should be correspondingly considered so that network marketing strategies and methods can be improved pointedly. There are three points of contribution in this essay. Firstly, it opens a new view of research which is the view of process to study E-commerce diffusion and it proposes E-commerce measurement manner so as to make clear how E-commerce innovation to support business activities in tourism enterprises. Secondly, it designs a measurement index system of tourist E-commerce diffusion so as to scientifically figure out tourist E-commerce in setting business activities, offering a computing method of tourist E-commerce innovation diffusion so as to reveal the range and degree of tourism enterprises developing E-commerce in business activities.

\section{References}

[1] Magal, S.R., Feng, M., Essex, P.A., 2001. An exploratory study of Web-based electronic commerce applications[J]. Journal of Information Technology Theory and Application 3 (5), 1-24.

[2] Lin, H.F., S.M. Lin. 2008. Determinants of e-business diffusion: A test of the technology diffusion perspective[J]. Technovation, 28(3): 135-145.

[3]Zhu K,Kraemer K.L,Xu S. 2006. The process of innovation assimilation by firms in different countries: A technology diffusion perspective on e-business[J]. Management Science, 52(10):1557-1576.

[4] Hameed, M.A. et al. 2012. A conceptual model for the process of IT innovation adoption in organizations[J]. Journal of engineering and technology management, 29(3): 358-390.

\section{Profile of the Author:}

Xiya Wang(1965-), female, Institution of Business, Xi'an Peihua University, Associate Professor. Research Interests: Tourism Management, Bilingual Education 